\title{
Mercury Speciation in Contaminated Soils from Old Mining Activities in Mexico Using a Chemical Selective Extraction
}

\author{
Irma Gavilán-García, ${ }^{* 1,3}$ Elvira Santos-Santos, ${ }^{1}$ Luis R. Tovar-Gálvez, ${ }^{3}$ Arturo Gavilán-García, ${ }^{2}$ \\ Sara Suárez, ${ }^{1}$ and Jesús Olmos ${ }^{1}$ \\ ${ }^{1}$ Unidad de Gestión Ambiental, Facultad de Química, Universidad Nacional Autónoma de México, Ciudad Universitaria 04510, \\ Coyoacán, México D.F. Phone: (52-55) 5622-37-45, Fax: (52-55) 5622-37-45, irmac@servidor.unam.mx \\ 2 Instituto Nacional de Ecología, Periférico 5000, Col. Insurgentes Cuicuilco, C.P. 04530, Delegación Coyoacán, México D.F. \\ Phone: (52-55) 5424-64-39 FAX: (52-55) 5424-54-02 \\ 3 Centro Interdisciplinario de Investigaciones y Estudios sobre Medio Ambiente y Desarrollo (CIIEMAD), Instituto Politécnico \\ Nacional, Calle 30 de junio 1520, Col. Barrio La Laguna Ticomán, Delegación Gustavo A. Madero, México D.F.
}

Received August 4, 2008; Accepted December 5, 2008

\begin{abstract}
Amalgamation was heavily used in mining since 1557 in Spanish Colonies. In Mexico and other parts of Latin-America, this process generated tailings which were left aside in the mine backyards. In the valley of Zacatecas, tailings were carried out of the mines due to the run-off from the mountains and contaminated most of the Zacatecan Valley which most important economic activity is agricultural (crop and livestock raising). The main concern in this area is the high level of total mercury found in previous studies. So far, various research studies have been conducted in Mexico to identify the contamination by total mercury in contaminated soils. However, research has not been developed to determine the available fraction by an analysis of the chemical species present in contaminated sites, which represent a risk to human health and the environment. The aim of this study is to develop a mercury sequential chemical extraction methodology with appropriate conditions for identifying: 1) water-soluble fraction, 2) elemental fraction, 3) interchangeable fraction, 4) strongly bound fraction, 5) organic fraction, 6) fraction as sulphides and 7) residual fraction. With this, it might be determined if the mercury species present in mining soils in the state of Zacatecas, Mexico represent a potential risk because of its mobility in the different environmental compartments. Results show that chemical species in the towns of Osiris and La Zacatecana $(\mathrm{HgS}$ and amalgamated mercury) have high stability and low mobility.

Key words: Mercury speciation, Soil contamination, Mining wastes, Chemical selective extraction.
\end{abstract}

\section{Introduction}

In nature, mercury is easily transformed into methyl-mercury by the action of microorganisms. This mercury species are dangerous since accumulation strongly occurs in aquatic biota, resulting in the contamination of fish and further on in higher levels on the food chain, which can lead to health problems. Once released into the atmosphere, mercury undergoes a series of chemical reactions that cause $\mathrm{Hg}$ (II) species to be deposited in the soil over the short or medium term; they are transformed by the environmental conditions in the soil $(\mathrm{pH}$, temperature, humic acid content, microorganisms), favouring the formation of organic and inorganic compounds, which display different mobility in the soil [1-4].
Resumen. El proceso de amalgamación fue ampliamente utilizado en la minería desde 1557 en las colonias españolas. En México, y otras partes de América Latina, se generaron jales, los cuales fueron abandonados en los patios de las minas. En el valle de Zacatecas, los jales fueron arrastrados fuera de estos sitios, contaminando la mayor parte del valle, el cual tiene como actividad económica principal la agricultura. La principal preocupación en esta área es el alto nivel de mercurio encontrado en investigaciones anteriores. Hasta ahora, se han desarrollado diversos estudios en México para identificar la contaminación por mercurio total en suelos contaminados. Sin embargo, no se ha desarrollado investigación para determinar la fracción disponible mediante el estudio de las especies químicas presentes en sitios contaminados, lo cual representa un riesgo a la salud y al ambiente. El objetivo de este estudio es el desarrollo de una metodología de extracción química secuencial con las condiciones adecuadas para identificar: 1) fracción soluble en agua, 2) fracción elemental, 3) fracción intercambiable, 4) fracción fuertemente enlazada, 5) fracción orgánica, 6) fracción como sulfuros y 7) fracción residual. Con esto, se busca determinar si las especies de mercurio presentes en los suelos contaminados del estado de Zacatecas, México, representan un riesgo potencial por la movilidad de las especies en los diversos compartimentos ambientales. Los resultados muestran que las especies químicas presentes (HgS y mercurio amalgamado) tienen alta estabilidad y poca movilidad en las comunidades de Osiris y La Zacatecana.

Palabras clave: Especiación de mercurio, contaminación de suelo, residuos mineros, extracción química selectiva.

Natural mercury emissions occur mainly in the form of elemental mercury. As for anthropogenic emissions, these are dominated by industrial processes and combustion sources with variable mercury content in the form of both elemental mercury and oxidized forms [5-8].

In Mexico, mercury contamination is related to the production of silver in colonial times using the technique of mercury amalgamation with in the «patio» process, mainly in the state of Zacatecas, where it was used extensively between 1570 and 1820 [9], and where the residues produced were dispersed by the rivers in the region and deposited in low-lying areas in the Zacatecas Plateau, which is nowadays used for crops and livestock farming. There have also been tailing-processing activities since 1920 to recover the precious metals in 
this soil. This has given rise to an increase in public concern over the stability of these reprocessed tailings, in particular in the chemical form of residual mercury. So far, various research studies have been conducted in Mexico to identify the total mercury contamination in soils. However, there has never been an attempt to determine the available fraction by an analysis of the chemical species present in contaminated sites, which could represent a risk to human health and the environment [10-12].

Direct speciation methods might look as a good option to identify chemical species for a single element. However, there are few techniques suitable for complex matrixes such as soils. In case of water, UV-visible or fluorometry techniques have been successfully used but have shown little sensibility/selectivity for complex matrixes. In case of soils, some optical techniques have been successfully used such as X-ray Diffraction (XRD), Electronic Microscopy Coupled to Energy Dispersion X-ray Spectroscopy (SEM-EDS), Electronic Microscopy Coupled to Wave-length Dispersion X-ray Spectroscopy (SEM-WDS), Sweep Electronic Microscopy (SEM) and Transmission Electronic Microscopy Coupled to an Electronic Diffraction Selector (TEM-SAED) but these still have limited detection limits and show problems to identify polymorphic chemical forms [7].

In developed countries, chemical speciation methods have been used since the eighties for different metal speciation, such as: Tessier et al (1979) [13] for particulate trace metals (Cd, Co, Cu, Ni, Pb, Zn, Fe and Mn), Davidson et al (1998) [14] for heavy metals from industrially contaminated land (Cd, $\mathrm{Cr}, \mathrm{Cu}, \mathrm{Pb}, \mathrm{Mn}, \mathrm{Ni}, \mathrm{V}$ and $\mathrm{Zn}$ ), and Rauret et al (1999) [15] for reference materials $(\mathrm{Cd}, \mathrm{Cr}, \mathrm{Cu}, \mathrm{Ni}, \mathrm{Pb}$ and $\mathrm{Zn})$. However, none of these include mercury and are not suitable for mercury speciation.

On the other hand, only few sequential chemical speciation methods consider the separation of mercury in five fractions by dissolving contaminated samples into different extractive media, mainly: 1) water-soluble species; 2) interchangeable species; 3) humic/fulvic species; 4) organic sulphides; and 5) residual fraction [16-20]. However, some studies have been reported for selective extraction of mercury by pyrolisis [21].

The use of the above-mentioned methods, as described in the literature, do not consider the identification of some mercury species commonly found in amalgamation tailings generated during the Spanish Colony, particularly elemental mercury, which is drawn in two fractions of the commonly used methods (interchangeable and humic/fulvic fraction); thus the need is presented for the development of a more specific methodology that consider a bigger number of fractions in order to identify the chemical species of mercury present amalgamation tailings and to determine the available fraction that could represent a potential risk to human health and the environment, testing the methodology on a contaminated site in the state of Zacatecas, Mexico.

The main objective of this study is to develop a mercury sequential chemical speciation methodology with appropriate conditions for identifying: 1) water-soluble fraction, 2) ele- mental fraction, 3) interchangeable fraction, 4) strongly bound fraction, 5) organic fraction, 6) fraction as sulphides and 7) residual fraction. Identification of these fractions is important due to the fact that they better represent the mercury mobility pattern in environmental compartments leading to a potential risk from amalgamation tailings.

\section{Methodology}

\section{Description of the Study Area}

The study site was selected from those sites indicated by previous research conducted in the valley of Zacatecas [22] as having the greatest concentrations of total mercury, and covers an approximate area of $8 \mathrm{~km}^{2}$ in the towns of Osiris and $\mathrm{La}$ Zacatecana. The border limits of the site area are marked by the points $\left(\mathrm{N}-22^{\circ} 45.180^{\prime}, \mathrm{W}-102^{\circ} 26.105^{\prime}\right)$, (N-22 ${ }^{\circ} 46.216^{\prime}$, $\left.\mathrm{W}-102^{\circ} 27.177^{\prime}\right),\left(\mathrm{N}-22^{\circ} 42.533^{\prime}, \mathrm{W}-102^{\circ} 29.859^{\prime}\right)$ and (N-22 ${ }^{\circ}$ $\left.44.799^{\prime}, \mathrm{W}-102^{\circ} 30.061^{\prime}\right)$. The most important economic activity in this area is agricultural (crop and livestock raising) due to the run-off from the mountains and the influence of the Plata River, which flows toward the La Zacatecana dam [23-24].

The type of soil is sandy clay with granular structure and soft consistency, reddish to greyish brown color, good internal drainage, and stoniness from 0 to $10 \%$ without rockiness, with $\mathrm{pH}$ from 7.0 to 8.0 [25].

\section{Soil Sampling}

The number of samples, $n$, was calculated using a statistic inference according to McBean (1998) [26], with the formula: $n=\left[Z \alpha^{2} * p^{*}(1-p)\right] / d^{2}$. In this design, a 95\% confidence interval was established (1-á) and a $Z a ́$ of 1.96 was calculated. Previous studies in the state of Zacatecas [22,27-29] indicate that $1 \%$ of the samples analyzed showed mercury concentrations above the recommended limit of $23 \mathrm{mgkg}^{-1}$ for agricultural soil [30], which corresponds to a proportion value $p$ of 0.01 ; further, taking these same studies as a basis, a precision value $d$ of $4 \%$ was established. Thus, the number of samples, $n$ $=22.81$, was calculated.

Based on the calculation of the number of samples, a decision was made to make a systematic, judicious sampling in which two 2 X $2 \mathrm{~km}$ grids were established within the towns of Osiris and La Zacatecana, respectively, covering a total area of $8 \mathrm{~km}^{2}$, in order to have a regular pattern for the sampling area. Sampling was made in each grid, situating points at each 500$\mathrm{m}$ interval. Precise positioning and adjustment was developed, so that 23 samples were taken for the town of Osiris (OM-1 to OM-23) and 24 for the town of La Zacatecana (ZM-1 to ZM24), as indicated in Figure 1.

This pattern was selected so as to completely cover the area and reduce errors in the model for interpolating data (IDW Interpolation Model) [31-32]. The grid samples were taken in fields with active cultivation of corn, bean and chilli crops. The soil samples $(300 \mathrm{~g})$ were collected at a depth of $0-15 \mathrm{~cm}$ 


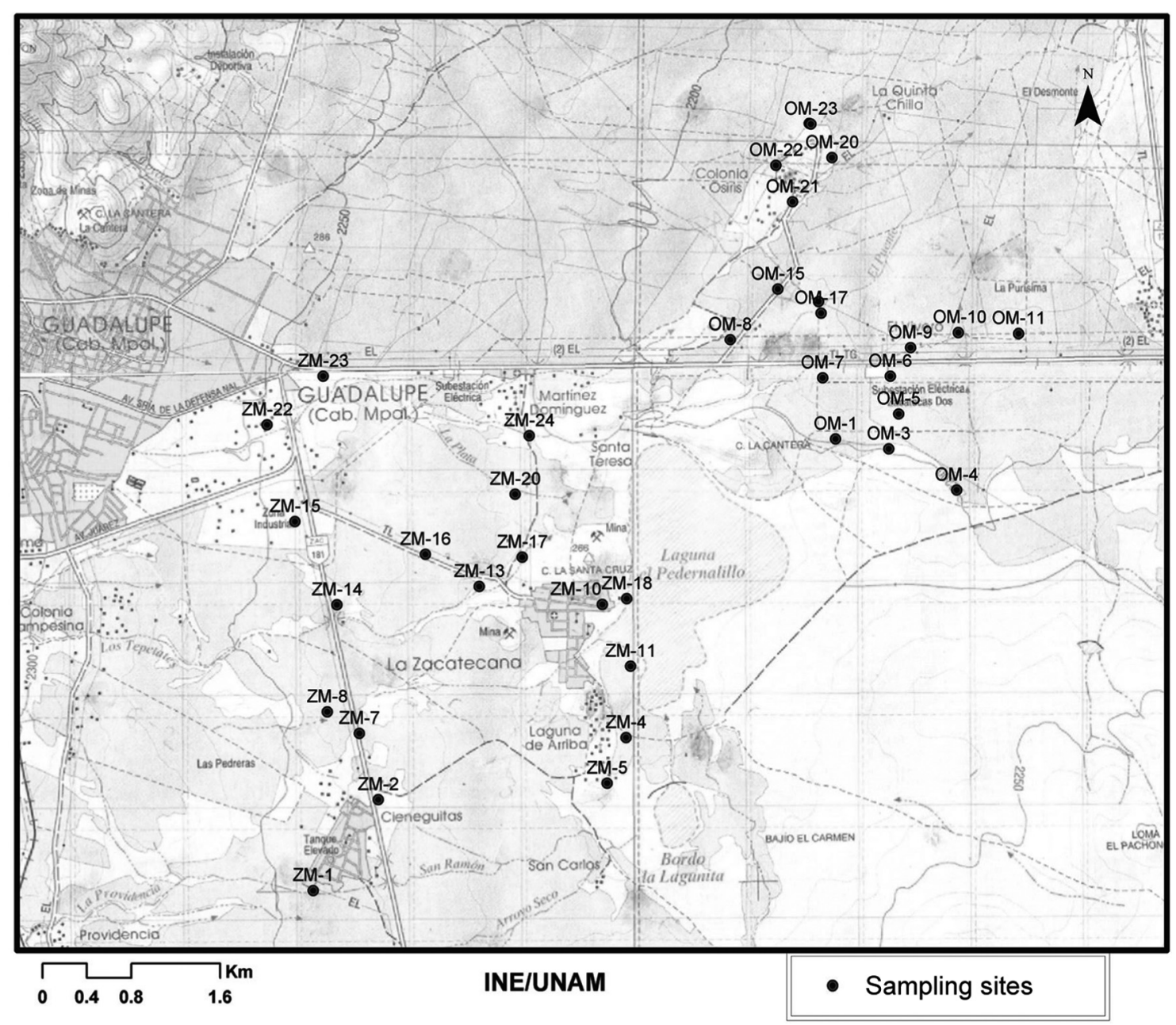

Fig. 1. Location of the points of soil sampling in the towns of Osiris (OM) and La Zacatecana (ZM)

in order to identify the profile of surface contamination and mercury absorption [33-34]. Topographical maps were used to come as close as possible to the sampling sites programmed in the grid (Figure 1).

\section{Analysis of Total Mercury Concentration}

The samples were dried at ambient temperature for $48 \mathrm{hrs}$ and passed through a mesh sieve for a particle size of $2 \mathrm{~mm}$. The total mercury concentration was analyzed by Cold Vapour Atomic Absorption Spectrophotometry (CVAAS). Microwave digestion was carried out with the addition of $3 \mathrm{~mL}$ of concentrated $\mathrm{HNO}_{3}$ and $10 \mathrm{~mL}$ of de-ionized water (Type $3 \mathrm{II}$ ) with $0.5 \mathrm{~g}$ of the sample. The mixture was heated at $121{ }^{\circ} \mathrm{C}$ and at a pressure of 0.98 atm for 15 minutes and then cooled to ambient temperature. It was then diluted to a volume of 25 $\mathrm{mL}$ with de-ionized water; $10 \mathrm{~mL}$ of concentrated $\mathrm{H}_{2} \mathrm{SO}_{4}$ was added before performing the analysis. Next, a few drops of a saturated solution of $\mathrm{KMnO}_{4}$ were added, and then $6 \mathrm{~mL}$ of a sodium chloride-hydroxylamine sulphate solution were added in order to reduce the excess permanganate, according to EPA SW 846 method 7471B [35]. The results were expressed as the average of the triplicate analysis of the samples, in milligrams of mercury per $\mathrm{kg}$ of dry soil. A value of $23 \mathrm{mgkg}^{-1}$ for mercury concentration in the soil was taken as the reference, as established in NOM-147-SEMARNAT/SSA1-2004.

\section{Sequential Chemical Speciation Method}

The strategy followed for conducting the experiment began with a review of the speciation methods reported in the literature [13,17,19,36-37]. We then proceeded to select those that could be applied and reproduced with the available infrastructure in a standard laboratory, and the performance level of each extraction method was observed by means of tests with Aldrich-brand analytical reactive grade mercury salts $(\mathrm{HgS}$, $\mathrm{HgSO}_{4}, \mathrm{HgO}, \mathrm{HgCl}_{2}$ ) in a prepared soil matrix. Each test carried out was done in triplicate.

Based on the results obtained with the prepared samples, an integrated methodology was established in order to identify a greater number of fractions in order to include the different routes of transport of mercury and the environment as well as the easily absorbed species by the organism taking the results obtained with the Ebinghaus (1999) [36] and Bloom et al 
(2003) [19] methods as the basis, with some adjustments in the extraction stages, chemicals used and reaction time so that the efficiency could be increased during the experiment and the sample losses considerably minimized.

The integrated methodology for sequential chemical speciation was applied to the contaminated soil samples that showed a total mercury concentration above the limit recommended by the regulations.

In the first part of the method, Extraction of watersoluble species $(\mathbf{F 1}), 50 \mathrm{~mL}$ of de-ionized water was added to the original sample and shaken for 120 minutes. The mixture was centrifuged for 20 minutes at 3000 RPM, decanted, and the mercury concentration in the supernatant was analyzed by Cold Vapour Atomic Absorption Spectrophotometry (CVAAS). The residue was then set aside for the next stage (F2).

Elemental Mercury (F2): the residue from stage F1 was heated to $180{ }^{\circ} \mathrm{C}$ in a muffle to separate out the metallic mercury; to prevent contamination, the recipient was covered with a watch glass containing activated charcoal to captures mercury vapour; then the quantity of mercury remaining in the residual solid was measured by CVAAS after acid digestion; to obtain the value of elemental mercury (F2), the concentration extracted in stage F1 and the concentration of mercury in the residue from this stage was subtracted from the total mercury concentration. The residue was set aside for the next stage (F3).

Extraction of exchangeable species (F3): $50 \mathrm{~mL}$ of magnesium chloride solution was added to the second fraction of residue from stage $\mathrm{F} 1$ and shaken at ambient temperature for 2 hours. The sample was centrifuged for 20 minutes at 3000 RPM and then the supernatant was decanted to measure the quantity of mercury by CVAAS. The residue is set aside for the following stage (F4).

Extraction of strongly bound species (F4): $50 \mathrm{~mL}$ of hydrochloric acid was added to the residue from stage F3 and shaken for 2 hours at ambient temperature. Then the sample was centrifuged for 20 minutes at 3000 RPM and the supernatant was decanted to measure the quantity of mercury by CVAAS. The residue was set aside for the next stage (F5).

Extraction of organic mercury (F5): $25 \mathrm{~mL}$ of $0.2 \mathrm{M}$ sodium hydroxide was added to the residue from stage $\mathrm{F} 4$, and the mixture was shaken at ambient temperature for 2 hours. Then $25 \mathrm{~mL}$ of a $4 \%(\mathrm{v} / \mathrm{v})$ solution of glacial acetic acid was added, and the mixture was shaken at ambient temperature for 2 hours. The sample was centrifuged for 20 minutes at 3000 RPM, and the supernatant was decanted to measure the quantity of mercury by CVAAS. The residue was set aside for the next stage (F6).

Extraction of the sulphide fraction (F6): $25 \mathrm{~mL}$ of a saturated solution of sodium sulphide was added to the residue from stage F5, and the mixture was shaken at ambient temperature for $24 \mathrm{~h}$. Then the sample was centrifuged for 20 minutes at
3000 RPM. The supernatant was separated and set aside. $25 \mathrm{~mL}$ of de-ionized water was added to the solid, and the sample was centrifuged for another 20 minutes at 3000 RPM. The supernatant was decanted and mixed with the supernatant obtained previously. The residue was set aside for the next stage (F7).

The quantity corresponding to the mercury sulphide fraction (F6) was obtained subtracting F1, F2, F3, F4, F5 and F7 fractions from the total mercury concentration, difference is $\mathrm{HgS}$ since excess sulphide might generate interference in CVAAS analysis.

Extraction of residual mercury (F7): digestion with $5 \mathrm{~mL}$ of $\mathrm{HNO}_{3}$ conc. and 15 of acid hydrochloric concentrate was carried out on the residue from stage $\mathrm{F} 6$, heating it at $85^{\circ} \mathrm{C}$ for 45 minutes. Next, it was centrifuged for 20 minutes at 3000 RPM and the supernatant was decanted, increasing it to a volume of $50 \mathrm{~mL}$ using hydrochloric acid $3 \mathrm{~N}$, and the analysis of the quantity extracted by CVAAS was then performed.

The flow chart for the procedure is shown in Figure 2.

According to the literature [36,38], the mercury species found in the seven speciation stages are as follows: F1) Water soluble species: $\mathrm{HgCl}_{2}$, F2) Elemental species: Amalgamated Hg, F3) Exchangeable species: $\left.\mathrm{HgSO}_{4} \& \mathrm{HgO}, \mathrm{F} 4\right)$ Strongly bounded species: Hg bounded to Fe \& Mn, F5) Organic species: Organic Hg, F6) HgS, and F7) Residual: HgSe \& residual.

\section{Quality Control and Quality Assurance in the Laboratory}

Laboratory analysis was carried out in triplicate samples in a PerkinElmer Atomic Absorption Spectrometer model 3110 with an ACE-90 autosampler and an ACE-60 burner. For calibration of the equipment, certified Aldrich-brand mercury standards were used. The technique used for the analysis was hydride-generation atomic absorption spectrophotometry with a detection limit for mercury of $0.31 \mathrm{mg} / \mathrm{L}$. Laboratory material and reagents were used as specified in EPA SW 846 method 3050B/7471B [35,39].

The proposed speciation method was tested using a prepared soil sample with standard concentration of the different species of mercury considered in the method. The reference material was developed in cooperation with Mexican Center of Metrology.

Triplicate blank samples were prepared for the prepared soil matrix (Kaolin) prior to addition of reactive grade mercury salts $\left(\mathrm{HgS}, \mathrm{HgSO}_{4}, \mathrm{HgO}, \mathrm{HgCl}_{2}\right)$ for each test developed with speciation methods reported in literature. This was also done for the testing of the proposed speciation method.

\section{Interpolation Method}

An inverse-distance weighted (IDW) interpolation algorithm was used by means of the ARC GIS 8.3, 2003 program in order to model iso-concentration areas using the information obtained from the total mercury analysis for the towns of Osiris and La Zacatecana (OM-1 to OM-23 and ZM-1 to 


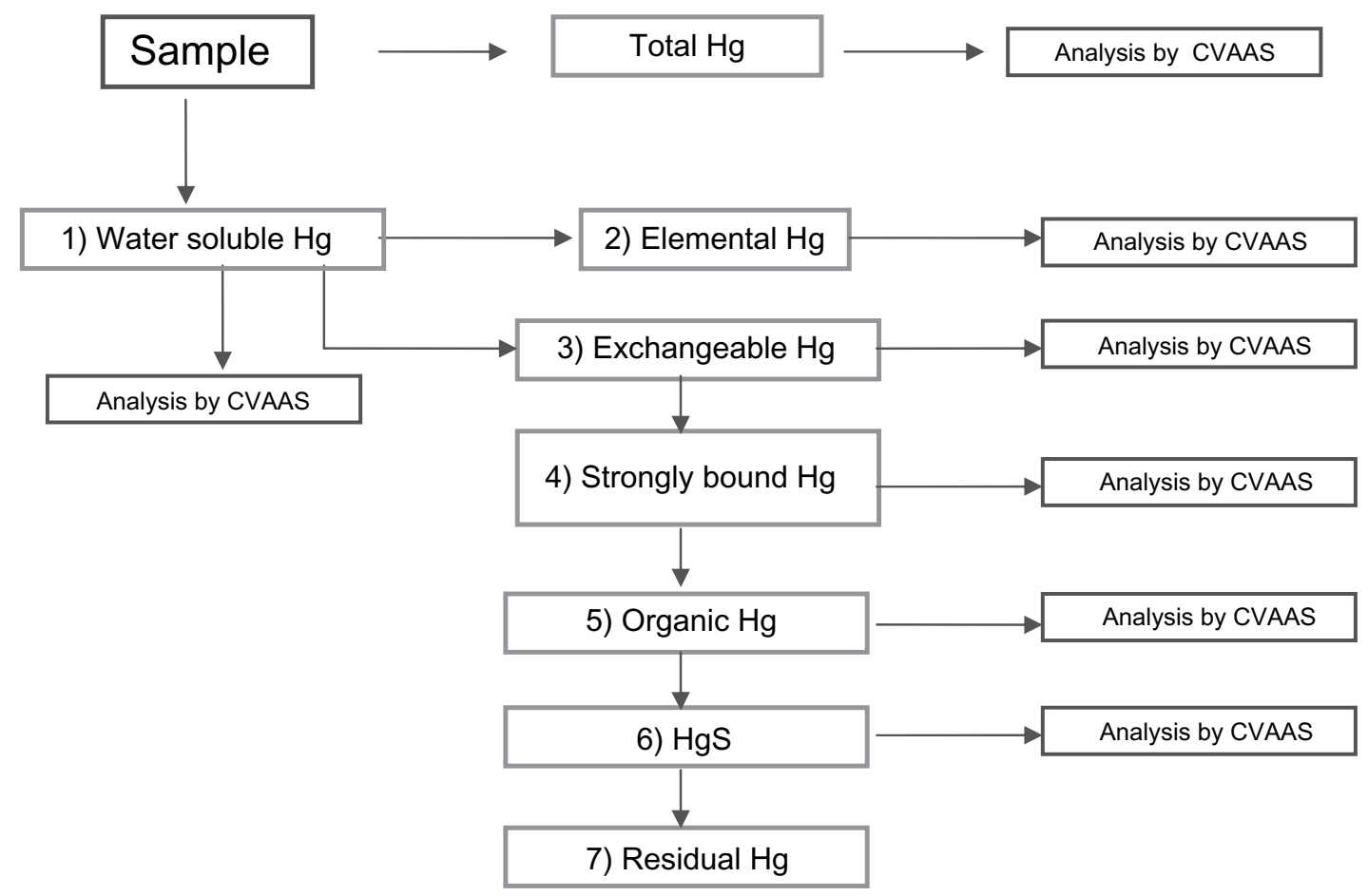

Fig. 2. Integrated method of mercury sequential chemical speciation.

ZM-24), given the high variability of the data obtained (Figure 3 ). The values of the iso-concentration curves were estimated by averaging the concentration values at the sampling points located in the vicinity of each modelling cell used by the program, and assuming that each sampling point has a local influence that decreases with distance, thus representing the fact that the points found in the proximity have a greater proportion that those farther away. A power of two was established to give greater weight to the near points and give greater detail in the resulting surface.

\section{Correlation of the Results}

In preparing the proposed chemical speciation methodology, the level of correlation was evaluated between the integrated method and the Ebinghaus and Bloom speciation methods, where values of $\mathrm{n}=56$ (considering seven fractions for speciated samples: OM-7, OM-8, OM-15, OM-16, OM-17, OM-22, ZM-18 and $\mathrm{ZM}-20$ ) and of $\mathrm{p}<0.05$ were used to identify the speciation efficiency for each of the stages proposed by each method [26].

\section{Results and Discussion}

\section{Analysis of the Total Mercury Concentration}

Results of the analysis of the total mercury concentration in the samples taken in the town of Osiris showed that the sites identified by codes OM-7, OM-8, OM-15, OM-16, OM-17, and OM-22 exceed the limit established for mercury by NOM147-SEMARNAT/SSA1-2004; it was also found that samples ZM-18 and ZM-20 taken in the town of La Zacatecana (Table 1) also exceed the limit permitted by this standard.

The highest total mercury concentration of the town of Osiris corresponded to samples OM-8 and OM-15. These exceed the level established in NOM-147-SEMARNAT/SSA12004 by $400 \%$ and $440 \%$, respectively. Since these sites are on farming lands, there is a potential risk of contaminating the crops, which would then be a potential route of entry to the organisms, when consumed.

In addition, there is considerable risk to the population through inhalation in the area where sample coded as OM22 was taken, which is in the center of the town of Osiris. However, since there is only one sample from the site, a detailed analysis should be made to confirm the high values of mercury concentration found.

Regarding the samples from the town of La Zacatecana, the total mercury concentration found in sample coded as ZM18 slightly exceeds the limit established in the standards, while sample ZM-20 exceeds this limit by 300\%. For this reason, it was considered of vital importance to subject these samples to the sequential chemical speciation procedure in order to proceed to identify the available fraction of mercury.

\section{Sequential Chemical Speciation}

Ebinghaus et al (1999) [36], Bloom (2003) [19], and Biester \& Scholz (1997) [18] speciation methods were tested with 


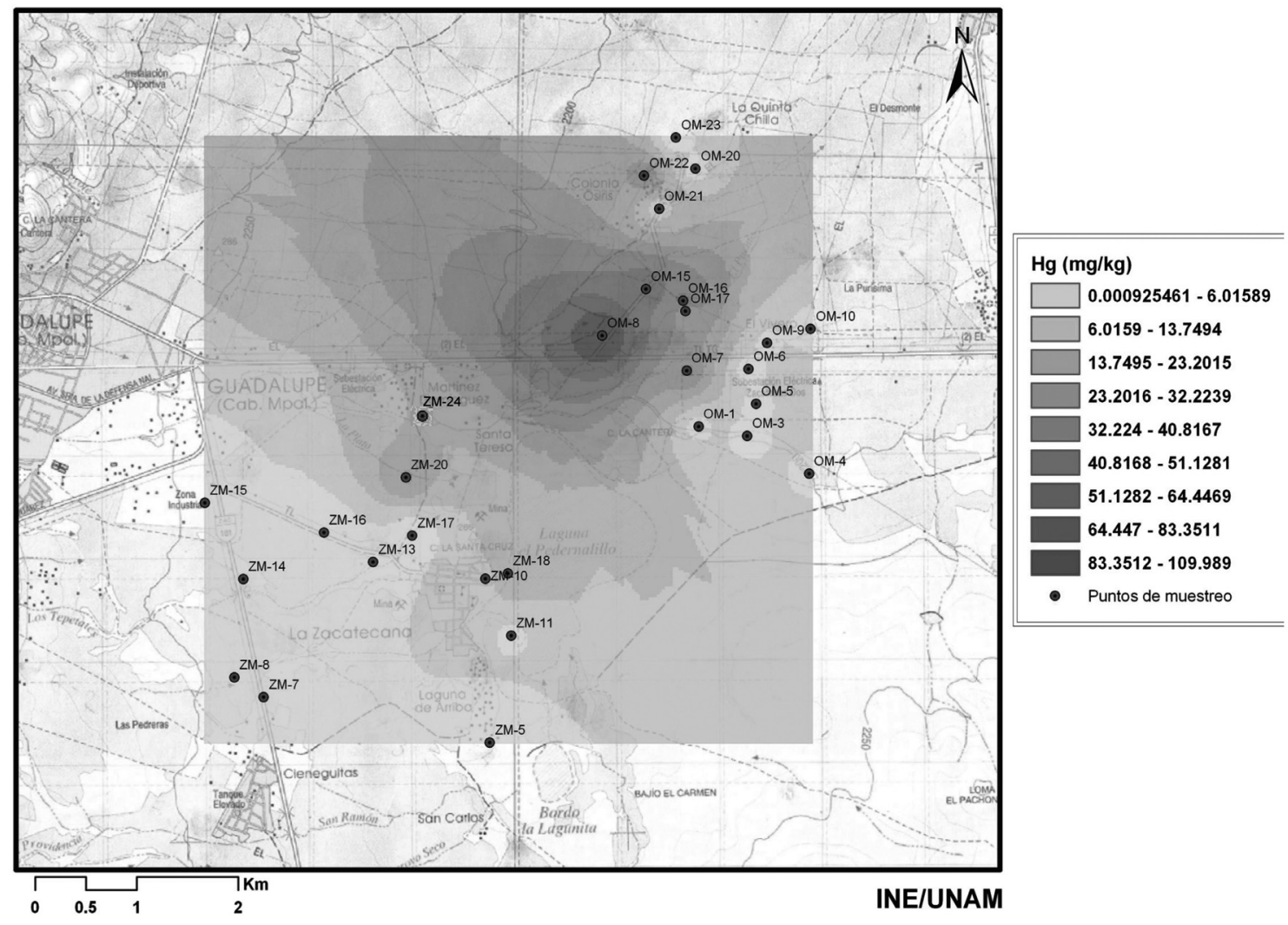

Fig. 3. Iso-concentration curves for total mercury in Osiris (OM) and La Zacatecana (ZM) soils.

artificial soil samples with the individual mercury salts: $\mathrm{HgO}$, $\mathrm{HgSO}_{4}, \mathrm{HgCl}_{2}$, and $\mathrm{HgS}$. Analysis were developed by atomic absorption spectrometry. Results show that all methods have different performances for extraction of the mercury salt tested as seen in the Supplementary Material.

The results of the sequential chemical speciation using the proposed method in the contaminated soil samples for the towns of Osiris and La Zacatecana that showed a total mercury concentration above the limit recommended by the standards, show that the predominant fraction is identified as the fractions F2 and F4 related to elemental and strongly bound mercury, as well as the fraction F6 of mercury species as sulphides, as indicated in Table 2. These fractions are reported as highly stable, with low solubility and bio-availability, according to Ebinghaus (1999) [36] and Bloom (2003) [19].

The fractions that represent a greater potential risk (watersoluble, interchangeable and organic species) were found in low concentrations, according to the results of the speciation of contaminated soils in Osiris and La Zacatecana. It was found that the maximum concentration of water-soluble species was $3.53 \mathrm{mg} \mathrm{kg}^{-1}$ (OM-16), which is six times smaller than that established in the existing standards; in the case of interchangeable species, the maximum concentration was 9.89 $\mathrm{mg} \mathrm{kg}^{-1}$ (OM-7), which is two times smaller than that recommended by the standards in effect; finally, in the case of the organic species, the maximum mercury concentration was 6.16 $\mathrm{mg} \mathrm{kg}^{-1}$ (OM-8), which is three times smaller than the established limit. This might represent that the health and environmental risk is relatively low. However, a bio-accessibility research is being developed using In vitro physiological based tests with contaminated soils of Osiris and La Zacatecana.

The fractions that are found in a greater concentration than that recommended by NOM-147-SEMARNAT/SSA1-2004 are those corresponding to elemental/amalgamated mercury and mercury as sulphide. It was found that the maximum concentration of the species of amalgamated mercury was $53.41 \mathrm{mg}$ $\mathrm{kg}^{-1}$ (OM-16), which is $242 \%$ greater than that established by existing standards; in the case of species in the form of sulphides, the maximum concentration was $40.70 \mathrm{mg} \mathrm{kg}^{-1}$ (OM-8), which is $185 \%$ greater than that recommended by the standards in effect for total mercury in soils. However, studies carried out to evaluate the bio-availability of this type of compound in simulated human digestion systems have found a low degree of bio-accessibility of mercury in this medium, which represents a low risk for populations exposed to it [40]. It should be pointed out that there are few studies reported in the literature on the exposure to inhalable particles of amalgamated or sulphide's form mercury through inhalation, from mining residues, so that this research might be extended in order to establish clearly the degree of risk involved; some authors have identified the fact that, in particles smaller than $1 \mathrm{im}$, the different metallic species of lead, cadmium and zinc are found 
Table 1. Total mercury concentration in the sampling from the towns of Osiris $(\mathrm{OM})$ and La Zacatecana $(\mathrm{ZM})(\mathrm{mg} / \mathrm{kg})$

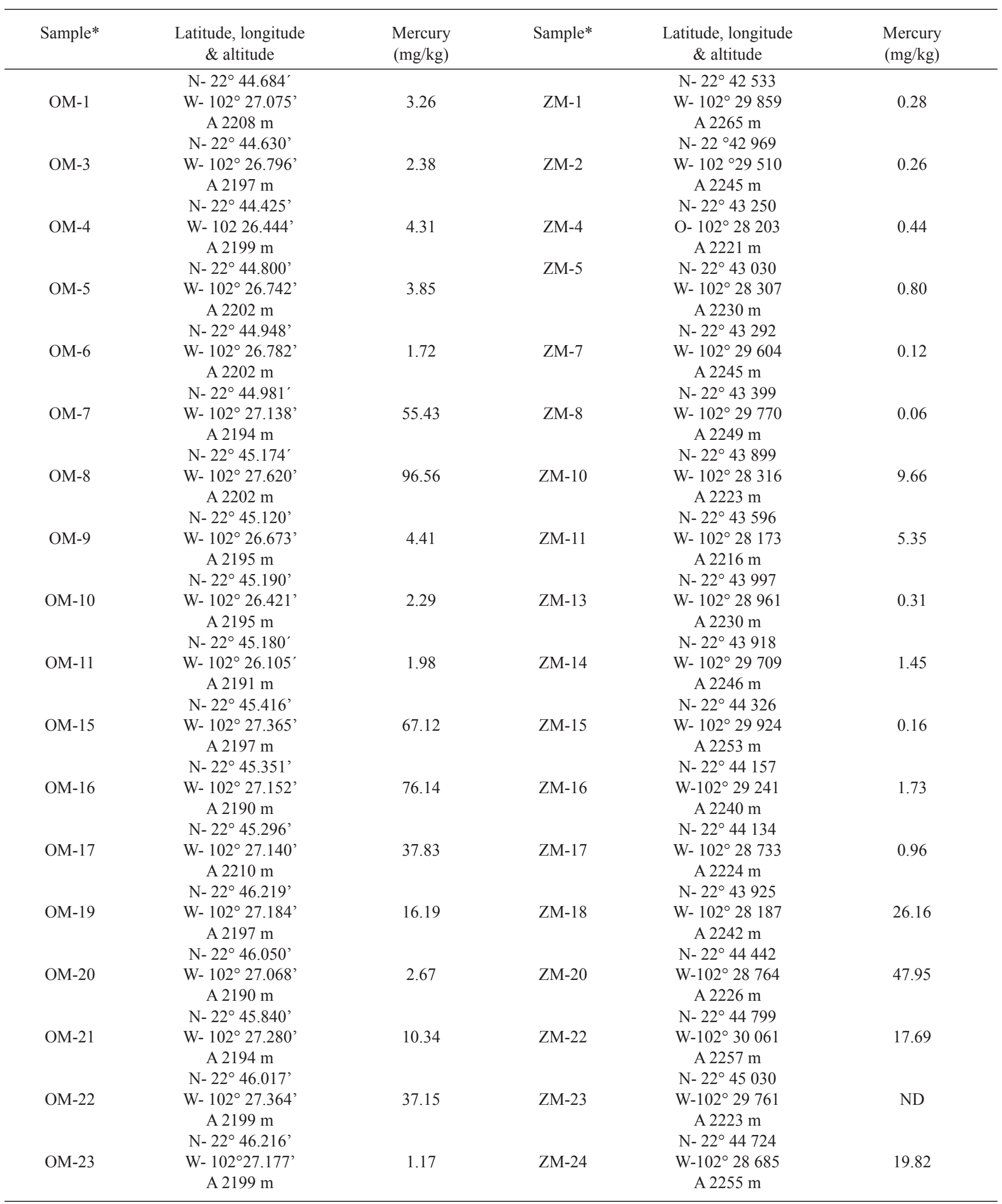

*Concentration of samples not shown were found at values under the detection limit of analytical equipment 
Table 2. Sequential chemical speciation of mercury in samples from Osiris (OM) and La Zacatecana (ZM) $(\mathrm{mg} / \mathrm{kg})$

\begin{tabular}{|c|c|c|c|c|c|c|c|c|}
\hline Sample* & $\begin{array}{c}(\mathrm{F} 1) \\
\text { Water soluble } \\
\text { species }\end{array}$ & $\begin{array}{c}(\mathrm{F} 2) \\
\mathrm{Hg}^{0} \\
\text { (elemental or } \\
\text { amalgamated) }\end{array}$ & $\begin{array}{c}(\mathrm{F} 3) \\
\text { Exchangeable } \\
\text { species }\end{array}$ & $\begin{array}{c}(\mathrm{F} 4) \\
\text { Strongly } \\
\text { bounded }\end{array}$ & $\begin{array}{c}(\mathrm{F} 5) \\
\text { Organic } \\
\text { species }\end{array}$ & $\begin{array}{l}\text { (F6) } \\
\mathrm{HgS}\end{array}$ & $\begin{array}{c}\text { (F7) } \\
\text { Residual }\end{array}$ & Total \\
\hline OM-7 & 0.64 & 16.42 & 9.89 & 12.17 & 0.61 & 13.27 & 2.43 & 55.43 \\
\hline DS & 0.09 & 1.57 & 1.24 & 1.60 & 0.33 & 1.18 & 0.12 & \\
\hline OM-15 & 1.11 & 25.88 & 3.21 & 0.74 & 0.22 & 33.02 & 2.94 & 67.12 \\
\hline DS & 1.15 & 0.22 & 0.78 & 0.05 & 0.06 & 1.11 & 0.11 & \\
\hline OM-16 & 3.53 & 53.41 & 1.15 & 2.10 & 0.11 & 11.11 & 4.73 & 76.14 \\
\hline DS & 0.63 & 1.96 & 0.35 & 0.19 & 0.02 & 1.49 & 0.15 & \\
\hline OM-17 & 0.39 & 23.22 & 1.10 & 1.87 & 0.12 & 8.51 & 2.62 & 37.83 \\
\hline DS & 0.16 & 0.35 & 0.81 & 0.03 & 0.41 & 0.06 & 0.06 & \\
\hline DS & 0.40 & 0.12 & 0.01 & 0.01 & 0.01 & 0.21 & 0.10 & \\
\hline ZM-20 & 1.64 & 35.16 & 1.31 & 1.04 & 0.04 & 5.28 & 3.48 & 47.95 \\
\hline DS & 1.26 & 0.33 & 0.05 & 0.03 & 0.01 & 1.10 & 0.05 & \\
\hline
\end{tabular}

*Samples with higher mercury concentration than established by NOM-147-SEMARNAT/SSA1-2004

Results are shown as the mean of triplicates

$\mathrm{DS}=$ Standard deviation

in a greater concentration from mining residues which represent a higher health risk by respiratory access to the organism [41].

Correlation was calculated by comparing the proportions of the Ebinghaus and Bloom speciation tests (taken as basis for the proposed method) versus the integrated method proposed in this research. As results, a correspondence value of 0.98 was found between Ebinghaus/Proposed and a correspondence value of 0.48 was found between Bloom/Proposed according to the Spearman correlation test [26]. This represent that the integrated method proposed is equivalent to Ebinghaus speciation test, but have some differences related to Bloom test, particularly in the number of steps. However, the integrated method showed better results compared to the prepared samples test, making possible to have a wider fractioning that represents in a better way the mercury species pattern found in the study sites.

From the results obtained, it is estimated that the potential risk is low, due to the high stability and low mobility of the mercury species in the sites under study. However, this research is only a basis for carrying out bio-availability studies into the different species, and for evaluating mercury absorption by plants and crops in the agricultural lands of the towns of Osiris and La Zacatecana. For this reason, a study is being conducted in order to evaluate the exposure routes and, with these results, to prepare an assessment of possible risks to vulnerable populations, so that adequate measures for mitigating present risks can be proposed to the corresponding authorities for their decision-making.

\section{Conclusions}

The importance of this study is related to the development of an integrated and efficient methodology for identifying the mercury species distributed according to groups of solubility (water-soluble, weak acids, organic acids, and aqua-regia) at a low cost and applied to characteristic soils which are contaminated with mining residues from amalgamation of gold and silver. The results indicate that the highest concentration of mercury on these sites corresponds to very stable chemical species with low mobility in air, soil and water and a high stability, such as: elemental (amalgamated) mercury, strongly bound mercury (mineralized and Fe and Mn oxy-hydroxides) and species in the form of sulphides and selenides.

\section{Acknowledgments}

The authors wish to thank: The Mexican National Institute of Ecology for financial and technical support; the Federal Office of the SEMARNAT in the State of Zacatecas for their technical support during field visits and sampling activities; the Mercury Programme of the United Nations Environmental Programme for financial support; and Project PAPIIT IN218305-2 «Especiación de mercurio en jales de minería del estado de Zacatecas» for financial support. 


\section{References}

1. Nriagu, J. The biogeochemistry of mercury in the environment. Elsevier/North Holland. Biomedical Press, 1979.

2. De Lacerda, L.; Solomons, W. Mercury from gold and silver mining: A chemical time bomb? Springer-Verlag Publishers, 1998.

3. Lovley, D. Microbial mercury reduction. Environmental microbemetal interactions. ASM Press, 2000, 177-197.

4. Environmental Protection Agency (EPA). Mercury study report to congress: Fate and transport of mercury in the environment. Volume III. EPA 452/R-97-005, 1997.

5. De Lacerda, L. Water, Air and Soil Pollut. 1997, 97, 209-221.

6. Mason, R.; Fitzgerald, W.; Morel, F. Geochim. Cosmochim. Acta. 1994, 58, 3191-3198.

7. Bernaus, A.; Gaona, X.; Valiente, M. J. Environ. Monit. 2005, 7, 771-777.

8. Environmental Protection Agency (EPA). Locating and estimating air emissions from sources of mercury and mercury compounds. EPA/454/R-93-023, 1993.

9. Johnson, D.; Whittle, K. J. Chem. Soc. Dalton Trans. 1999, 4239_ 4243.

10. Lang, M. The state monopoly of mercury in Colonial Mexico (1550-1710). Fondo de Cultura Económica, 1977, 35-60.

11. Camargo, J. Chemosphere 2002, 48, 51-57.

12. Brading, D.; Cross, H. Hispanic Am. Hist. Rev. 1972, 52, 545579.

13. Tessier, A.; Campbell, P.; Bisson, M. Anal. Chem. 1979, 51, 844851.

14. Davidson, C.; Duncan, A.; Littlejohn, D.; Ure, A.; Garden, L. Analyt. Chim. Acta. 1998, 363, 45-55.

15. Rauret, G.; Lopez-Sanchez, J.; Sahuquillo, A.; Rubio, R.; Davidson, C.; Ure, A.; Quevauviller, P. J. Environ. Monit. 1999, 1, 57-61.

16. Templeton, D.; Ariese, F.; Cornelis, R.; Danielsson, L.; Muntau, H.; Van Leeuwen, H.; Lobinski, R. Pure Appl. Chem. 2000, 72, 1453-1470.

17. Di Giulio, R.; Ryan, E. Water, Air Soil Pollut. 1987, 33, 205-219.

18. Biester, H.; Scholz, C. Environ. Sci. Tech. 1997, 31, 233-239.

19. Bloom, N.; Preus, E.; Katon, J.; Hiltner, M. Anal. Chim. Act. 2003, 479, 233-248.

20. Panyametheekul, S. 2004. Environmental Geochemistry and Health. 2004, 26, 51-57.

21. Sladek, C.; Gustin, M. Applied geochemistry 2003, 18, 567-576.

22. Santos, E.; Yarto-Ramírez, M.; Gavilán-García, I.; Castro-Díaz,
J.; Gavilán-García, A.; Rosiles, R.; Suárez, S.; López-Villegas, T. 2006. J. Mex. Chem. Soc. 2006, 50, 57-63.

23. Instituto Nacional de Estadística, Geografía e Informática (INEGI). Charts F13-6 of Zacatecas (Topography, water and underground water, Edafology, soil use). Mexico. 2001.

24. http://www.inegi.gob.mx/territorio/espanol/datosgeogra/fisigeo/ suelos.html, accessed in April, 2008.

25. SEMARNAT. Action plan for La Zacatecana dam for the contention of heavy metals. Mexico. 2002.

26. McBean, E. Statistical procedures for analysis of environmental monitoring data \& risk assessment. Prentice Hall PTR, 1998.

27. Iskander, F.; Vega-Carrillo, H.; Manzanares, E. Sci. Total Environ. 1994, 148, 45-48.

28. Pearson, R. Phase II - Stage I of the mercury task force study, Zacatecas, Mexico. North American Commission of Environmental Cooperation, 2003.

29. Ogura, T.; Ramirez, O.; Arrollo-Villaseñor, Z.; Hernández, M.; Palafox-Hernández, P.; García, A.; Quintus, F. Water, Air Soil Pollut. 2003, 147, 167-177.

30. http://www.semarnat.gob.mx/leyesynormas/Pages/normasoficialesmexicanasvigentes.aspx, accessed in October, 2008.

31. Ministry of Environment and Energy. Guidance on Sampling and Analytical Methods for Use at Contaminated Sites in Ontario, 1996.

32. ARC GIS 8.3. ESRI Geographic Information System and Mapping Software. IDW Interpolation Model, 2003.

33. Wander, M.; Yang, X. Soil Biol. \& Biochem. 2000, 32, 1151-1160.

34. Roldán, A.; Caravaca, F.; Hernández, M.; García, C.; SánchezBrito, C.; Velásquez, M.; Tiscareño, M. Soil Till. Res. 2003, 72, 65-73.

35. http://www.epa.gov/epaoswer/hazwaste/test/main.htm, accessed in June, 2008.

36. Ebinghaus, R.; Turner, R.; De Lacerda, L.; Vasiliev, O.; Salomons, W. Mercury contaminated sites: Characterization, risk assessment and remediation. Springer-Verlag Publishers, 1999.

37. Wallschläger, D.; Desai, M.; Spengler, M.; Wilken, R. J. Environ. Qual. 1998, 27, 1034-1044.

38. Kim, C.; Bloom, N.; Rytuba, J.; Brown, J. Environ. Sci. Technol. 2003, 37, 5102-5108.

39. Taverniers, I.; De Loose, M.; Van Bockstael, E. Trends in Analytical Chemistry. 2004, 23, 8.

40. Davis, A.; Bloom, N.; Que, S. Risk analysis. 1997, 17, 557-569.

41. Schaider, L.; Senn, D.; Brabander, D.; McCarthy, K.; Shine, J. Environ. Sci. Technol. 2007, 41, 4164-4171. 